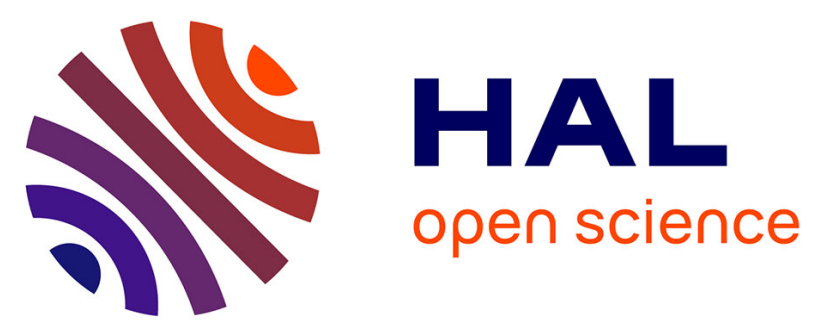

\title{
Effectiveness of a programme delivered in a falls clinic in preventing serious injuries in high-risk older adults: A pre- and post-intervention study
}

Hubert Blain, Fiona Dabas, Samia Mekhinini, Marie-Christine Picot, Stéphanie Miot, Jean Bousquet, Chokri Boubakri, Audrey Jaussent, Pierre Louis Bernard

\section{To cite this version:}

Hubert Blain, Fiona Dabas, Samia Mekhinini, Marie-Christine Picot, Stéphanie Miot, et al.. Effectiveness of a programme delivered in a falls clinic in preventing serious injuries in high-risk older adults: A pre- and post-intervention study. Maturitas, 2019, 122, pp.80-86. 10.1016/j.maturitas.2019.01.012 . hal-02885899

\section{HAL Id: hal-02885899 \\ https://hal.umontpellier.fr/hal-02885899}

Submitted on 21 Oct 2021

HAL is a multi-disciplinary open access archive for the deposit and dissemination of scientific research documents, whether they are published or not. The documents may come from teaching and research institutions in France or abroad, or from public or private research centers.
L'archive ouverte pluridisciplinaire HAL, est destinée au dépôt et à la diffusion de documents scientifiques de niveau recherche, publiés ou non, émanant des établissements d'enseignement et de recherche français ou étrangers, des laboratoires publics ou privés.

\section{(ㄷ)(1) $\$$}

Distributed under a Creative Commons Attribution - NonCommerciall 4.0 International 


\section{Highlights}

- Falls are a main cause of hospitalization, nursing home admission, and death in older subjects.

- Falls clinics have shown effectiveness in improving mobility and balance, and in reducing falls rates in older patients.

- Recurrent fallers and older fallers with functional disorders are at high risk of falls and injuries.

- The present pre-post study found fewer serious fall-related injuries in the 6 months following assessment in a fall clinic in high-risk older patients.

- The level of adherence to the main recommendations and of satisfaction with the programme was $>70 \%$.

\section{Effectiveness of a programme delivered in a falls clinic in preventing serious injuries in high-risk older adults: a pre- and post-intervention study}

Hubert Blain, MD, PhD, ${ }^{1,2,3,4}$ Fiona Dabas, MD, ${ }^{1}$ Samia Mekhinini, MD, ${ }^{1}$ MarieChristine Picot, MD, PhD, ${ }^{4}$ Stéphanie Miot, MD, PhD, ${ }^{1}$ Jean Bousquet, MD, PhD, ${ }^{2}$ Chokri Boubakri, MD, ${ }^{1}$ Audrey Jaussent, MD, PhD ${ }^{4}$, Pierre Louis Bernard, PhD ${ }^{2,3}$

\section{AUTHOR AFFILIATIONS:}

${ }^{1}$ Department of Internal Medicine and Geriatrics, University Hospital of Montpellier, Montpellier University, France

${ }^{2}$ MACVIA France

${ }^{3}$ EA 2991, Euromov, Montpellier University, France

${ }^{4}$ Department of Medical Information, University Hospital of Montpellier, Montpellier University, France

Corresponding author. Hubert Blain h-blain@chu-montpellier.fr

\section{ABSTRACT \\ OBJECTIVE}


To evaluate whether a multifactorial programme delivered in a real practice setting would help prevent serious fall-related injuries in high-risk older patients.

\section{DESIGN}

A 6-month pre-post intervention study in 134 fallers (81.6 \pm 7.2 years) consecutively referred to a fall prevention clinic after repeated falls in the previous year or after a fall associated with balance, gait, or strength disorders. The programme was delivered by a physiotherapist, an occupational therapist, a podiatrist, and a geriatrician based on a 3-hour fall risk assessment.

\section{RESULTS}

The proportion of patients with serious and moderate fall-related injuries was significantly lower in the 6 months after than in the 6-months preceding clinic attendance [8 (6.1\%) vs 40 (30.5\%), and $11(8.2 \%)$ vs 19 (14.2\%), respectively; $p<0.0001]$, as were the overall proportion of fallers $(32.1 \%$ vs $95.4 \% ; p<0.0001)$ and the number of falls per patient $(-5.2 \pm-20.4 ; p<0.0001)$. When compared with baseline, fear of falling at 6 months was reduced $(p<0.05)$, mobility was maintained, and the proportion of patients with an ADL score $\leq 2$ was increased (5.6\% vs $9.7 \%$ respectively; $\mathrm{p}<0.001)$. Adherence to the main recommendations and satisfaction with the programme were $>75 \%$ at 6 months post-clinic.

\section{CONCLUSIONS}

A multifactorial fall prevention programme delivered by a multidisciplinary geriatric team in older patients at high risk of falling helps to reduce over a 6-month period the risk of serious and moderate injuries related to falls, the risk of falling, and the fear of falling, and helps to maintain mobility and improve functional status.

ClinicalTrials.gov ID: NCT03737487.

Keywords: falls prevention clinic; falls; injurious falls; comprehensive geriatric assessment; ageing

\section{Introduction}


Falls are one of the main causes of decreased functioning, admission to emergency department, hospital and nursing homes, and death in older subjects [1]. Falls prevention is therefore a priority in promoting active and healthy ageing and reducing healthcare resource utilization in older subjects [2-4]. Randomized-controlled trials indicate that multiple component interventions, including exercise and another component such as education or home-hazard assessment, do not seem to be effective in preventing injurious falls in community-dwelling older persons at high risk of falling and in nursing home residents $[5,6]$. For older people at high risk of falling, especially those with recurrent falls, or in fallers with significant gait, balance or muscle strength disorders, current guidelines recommend an individualized assessment of risk factors of falls and a tailored multifactorial intervention programme. This includes exercise, gradual withdrawal of fall-risk-increasing-drugs (FRIDs), optimization of vision and health conditions, home safety interventions, multifaceted podiatry, and calcium and vitamin D supplementation if needed $[3,7]$. The efficacy of such a strategy for reducing injurious falls is however not fully demonstrated in randomized-controlled trials [6].

Falls clinics are one approach by which older people at risk of falls and injuries can be managed in real clinical practice, addressing all identified modifiable risk factors. While falls clinics have been reported in the literature since 1988, only one randomized-controlled trial has observed a significant reduction in fall-related injuries $(-26 \%)$ in patients among whom $45 \%$ had a history of fall in the previous year [8]. Before-after studies have been conducted to overcome ethical difficulties in conducting randomized-controlled trials in patients at high risk of injurious falls. Most of those pre-post design studies have observed an efficacy of falls clinics in improving balance, mobility, fear of falling [9-12], fall rates [11,12], and use of fall- 
related health services $[9,12]$. Only one pre-post study, conducted in 13 Australian falls clinics and 254 elders, has observed a $55 \%$ significant reduction of injurious falls 6 months after clinic attendance [11]. In those two previous studies with positive outcomes on injurious falls $[8,11]$, most fall-related injuries were bruising or other moderate injuries. Efficacy on serious fall-related injuries did not obtain significance, possibly due, for ethical reasons, to the insufficient representation of patients with high risk of injurious falls in the randomized-controlled trial [13] and to the low adherence for interventions, such as exercise programmes [10], and home and medication modification, in the pre-post intervention study [14].

In the present 6-month pre-post intervention study, we included older patients consecutively referred to a specialist falls prevention clinic after repeated falls in the previous year, or after a fall in the past 12 months associated with significant balance, gait, or strength disorders. The main objective was to determine, in those high risk patients, the effect on serious falls-related injuries of a tailored multifactorial programme delivered after a 3-hour assessment by a physiotherapist, an occupational therapist, a podiatrist, and a geriatrician. Secondary aims were to evaluate over the 6-month follow-up period the effect of the intervention programme on moderate injuries, falls rate, falls risk, fear of falling, mobility, ability to perform activities of daily living (ADL), patient's adherence to recommendations and patient's or caregiver's satisfaction with the programme.

\section{Method}




\section{Setting and participants}

The Montpellier falls prevention clinic (FPC) is a referral-based clinic specialized in the prevention of falls and fractures among patients aged 65+ (http://www.chumontpellier.fr/fr/crepc/). The FPC is a member of the European Commission in its European Innovation Partnership on Active and Healthy Ageing (EIP on AHA) A2 action plan [15]. The main mission of the clinic is to identify the underlying causes of the patients' falls, and to address all modifiable risk factors in collaboration with family physicians.

We analysed data from a cohort of patients aged 65 and over, consecutively referred to the FPC over a 11-month period after recurrent falls in the previous year, or after a fall in the past 12 months associated with gait, balance, or strength disturbance at baseline.

A fall was defined as an "unexpected event in which the participant comes to rest on the ground, floor, or other lower level" [7]. Injurious falls included falls complicated by serious or moderate injuries. Falls with serious injuries were those that caused fractures, head injuries requiring admission to hospital, joint dislocations, sprains accompanied by reduced physical function, other nonspecified serious joint injuries, and lacerations requiring sutures. Falls with moderate injuries were those that resulted in bruising, sprains, cuts, abrasions, or reduction in physical function for at least three days or in medical help [16].

A gait disturbance was defined by an inability of the patient to perform the Timed Up and Go test in less than 14 seconds [17]. A balance disturbance was defined by an inability of the patient to stand on one leg for at least 5 seconds [18]. A low muscle strength was defined by a grip strength of $37 \mathrm{~kg}$ or less for men and $21 \mathrm{~kg}$ or less for 
women [19]. As this is a cohort study, a STROBE checklist has been included in the supplementary materials.

\section{Multidisciplinary fall risk and geriatric comprehensive assessment}

All patients underwent the same multidisciplinary fall risk and geriatric comprehensive assessment by health care professionals of the clinic. The assessment was performed on a routine basis and included the following steps:

- Calculation of BMI based on height and weight, measured by a nurse to the nearest $0.5 \mathrm{~cm}$ and $0.1 \mathrm{~kg}$, respectively $\left(\mathrm{kg} / \mathrm{m}^{2}\right)$.

- A 40-min assessment of balance, walking speed, muscle strength, activity, and functional status by a physiotherapist using: (1) the Short Physical Performance Battery (SPPB), ${ }^{20}$ the Timed-Up-and-Go Test (TUG) [17], the Tinetti test [21], and both hands grip strength measurements with a Jamar hand dynamometer [19], (2) questionnaires to quantify the need for technical help for inside and outside walking (human aid, walking stick, walker, wheelchair), and (3) the activities of daily living (ADL) completed with the caregiver if necessary [22].

- A 40-min assessment by an occupational therapist, including a detailed questionnaire on social support, living situation and home environment, completed with the caregiver if necessary. Patients were categorized as not concerned, a little concerned, quite concerned, or very concerned by the risk of falling [23]. Cognitive function was assessed using the mini mental state examination (MMSE) that was considered normal when the score was 25 or higher. Cognitive disorder was categorized as severe when the MMSE score was less than 10, moderate between 10 and 19 and mild between 20 and 24. 
- A 20-min assessment by a podiatrist including an examination of the patient's feet and footwear.

- A 60-min assessment by a geriatrician including a description of previous falls in the previous year (number, injuries, circumstances), a review of current medications and medical history, and an in-depth examination of the patient to detect possible contributors or risk factors for falling (especially FRIDs, joint, ENT, psychiatric, neurological, pulmonary, gut or metabolic disorders, postural hypotension, and signs of osteoporosis, artery and heart diseases, including cardiac failure and carotid sinus hypersensitivity, signs of sleep apnoea, of urinary infections, retention or incontinence) [7].

- A blood collection with complete blood count (with serum electrolytes (natremia, glycaemia, kaliemia, calcemia), urea nitrogen and serum creatinine, C-reactive protein, transaminases and gamma-glutamyl transferase, thyroid-stimulating hormone, $25 \mathrm{OH}$ vitamin $\mathrm{D}$, electrocardiogram), or other investigations (dual-energy X-ray absorptiometry, for example) or specialist referral were performed upon request from the geriatrician. Patients without an eye examination in the past year were referred systematically to an ophthalmologist.

- A 20-min review meeting with the 4 healthcare professionals in order to prioritize recommendations to be provided.

The conclusion of the assessment was then summarized by the geriatrician for the patient or the caregiver and appropriate recommendations and prescription were provided. In patients with a TUG test $\geq 14$ seconds, prescriptions systematically included physiotherapy sessions (2 sessions per week for 6 months, including balance, gait, flexibility, and strengthening exercises adapted to baseline assessment, procedures to get up after a fall, and foot and ankle exercises). Patients 
with a TUG test $<14$ seconds were referred to "MACVIA-France Equilibre Prévention de la Chute Autonomie Santé", in order to register for community physical activity programmes organised for older adults at high risk of falling (one-hour exercise sessions twice a week for 6 months by trained staff) [15]. In patients with transport difficulties, physiotherapy at home was prescribed whatever the TUG result.

Patients were systematically given $80000 \mathrm{UI}$ oral vitamin D supplements and GPs were advised to adapt the treatment according to baseline blood vitamin $\mathrm{D}$ level or in compliance with national guidelines.

According to the patient's profile, other prescriptions included podiatry (lesion debridement, footwear advice, foot orthoses, for example), environment changes, adapted technical support, modification of drug use to optimize underlying conditions, to progressively withdraw FRIDs, and to treat osteoporosis. The likely diagnoses and recommendations were noted in the medical report that was handed over to the patient or the caregiver for the patient's GP, along with the prescriptions, and sent also by mail to the GP. Recommendations remained under the GP's control with the possibility of another consultation if needed. Patients or their legal representatives gave their consent to be interviewed by phone 6 months after the visit in order to provide information on the occurrence of new falls and falls-related injuries since the visit, on recommendations actually set up, on the patient's current functional status, and to express their view on the programme. A copy of the questionnaires used and an example of the routine assessment performed in the falls clinic are included in the supplementary materials. 


\section{Main outcome measures}

The primary outcome was the number of serious fall-related injuries in the 6 months post-clinic in comparison with the 6 months pre-clinic. Secondary outcomes included the occurrence of moderate fall-related injuries, of falls, technical help needed for inside and outside walking, fear of falling, ADL score, interventions actually set up among those proposed, and satisfaction with the programme.

Primary and secondary outcomes were collected 6 months after the clinic visit via a phone questionnaire administered to the patients or to their legal representatives by two independent researchers (two medical residents) who had no link with the falls clinic. When participants or their legal representatives had difficulties in specifying the type of injury related to a fall that occurred in the 6 months after the visit, consent was obtained from participants or their legal representatives to interview the GPs or the nurses to obtain further information. The study was approved by the Clinical Research Ethics Committee of the University Hospital of Montpellier (France)(IRB-MTP181016; ClinicalTrials.gov ID: NCT03737487).

\section{Sample size}

Considering a rate of $20 \%$ of serious falls-related injuries in the 6 -month period before clinic attendance, a sample of 102 subjects was found to be required to demonstrate a $50 \%$ reduction of serious falls-related injuries in the 6 months postclinic, with an alpha and beta error of $5 \%$ and a statistical power of $95 \%$. To allow for study drop-outs, there was an oversampling of $20 \%$, which determined a final minimum sample of 113 subjects. 


\section{Data analysis}

The qualitative variables were described with frequency and proportions for each category. The distributions of the quantitative variables were tested by the ShapiroWilk test and the description of these variables was specified using the mean with the standard deviation and/or the median, minimum and maximum values. The comparisons pre- versus post-intervention were made using the paired Student's test if the distributions were Gaussian. Otherwise, the Wilcoxon test for paired series was used. The evolution of the qualitative variables before and after intervention was tested with the Mc Nemar $\mathrm{Chi}^{2}$ test or the Bowker symmetry test if the response modalities were greater than 2 . The significance threshold was set at $5 \%$ for all tests used. The statistical analysis was performed at the epidemiology and clinical research unit of Montpellier University Hospital with SAS software version 9 (SAS Institute, Cary, N.C.).

\section{Results}

\section{Characteristics of the patients}

Among the 212 patients admitted to the clinic in 11 consecutive months, 160 had a history of recurrent falls in the previous year or of a fall associated with a balance, gait, or muscle strength problem. Twenty-three patients were lost to follow-up and 3 had incomplete data for at least one outcome. The 26 patients not included in the final analysis did not differ in age, gender, ADL, and living status from the patients entered in the analysis.

Baseline characteristics of the 134 analyzed patients are displayed in Table 1 and primary and secondary outcomes are displayed in Table 2. 


\section{Serious injuries}

The number of patients with at least one serious injury was significantly lower in the 6 months after vs preceding clinic attendance [8 (6.1\%) vs 40 (30.5\%); $\mathrm{p}<0.0001)]$. The types of injuries are reported in Table 3.

\section{Other outcomes}

The rate of patients with moderate fall-related injuries decreased significantly from $45.0 \%$ to $14.5 \%(p<0.0001)$. The rate of fallers was significantly lower 6 months after vs before clinic attendance (32.1\% vs $95.4 \%$, respectively; $p<0.0001)$.

The number of falls per patient was significantly lower 6 months after clinic attendance than 6 months before $(-5.2 \pm-20.4$ falls per patient, respectively; $p<$ $0.001)$.

Fear of falling was significantly lower at 6 months post-clinic when compared to baseline, and mobility was maintained. Ability to perform ADLs improved significantly (5.6\% had ADL score $\leq 2$ at baseline vs $9.8 \% 6$ months after clinic attendance; $\mathrm{p}<0.001)$. Figure 1 shows risk factors of falling documented during the assessment, with 2.2 risk factors identified per patient on average.

Adherence of patients to interventions was $>70 \%$, except for community exercises and home modifications (Table 4).

Except for the delay to obtain an appointment and the duration of the assessment and examination considered as too long by some patients and caregivers, more than $70 \%$ of patients or caregivers were satisfied with the pertinence of the assessment, the information given, and the recommendations provided (Figure 2). 


\section{Discussion}

In this 6-month pre-post intervention study conducted in older patients referred to a specialist falls prevention clinic after recurrent falls, or after a fall with significant gait, balance, or strength impairments, we observed that a tailored multifactorial programme may reduce the number of serious and moderate fall-related injuries, the number of falls and fallers, the fear of falling, and may maintain or improve mobility and ability to perform ADLs.

Our study has several strengths. As far as we know, this study is the first before-after study to show the efficacy of a falls clinic in preventing serious injuries in high risk older patients defined using current guidelines (fallers with recent history of recurrent falls or with gait, balance, or muscle strength disorder) $[3,7]$. The methodology used herein has been identical for all consecutive older patients and our patients have demonstrated a high level of adherence to the programme.

The present study does however have several limitations. This study is observational and without randomization. However, randomized-controlled studies generally exclude frail patients at the highest risk of falls and injuries and apply strict eligibility criteria that reduce the generalizability of their results in daily practice. On the other hand, pre-post studies conducted in patients recruited consecutively have the advantage of evaluating a real-world practice, operating within the context of usual care, and involving elders whatever their health and psychological status, and socioenvironmental characteristics. Present results reflect the real situation of a falls prevention clinic, and provide estimates of the result that can realistically be expected by the patient, the caregiver, and the GP referring patients at high risk of fall and injury to this kind of setting. 
Even if the information was recorded by using the same questionnaires at baseline and at 6 months after the visit, interviewer bias is a possible limitation of the present study. Indeed, pre-intervention data were collected by health care professionals from the clinic and post-intervention data were collected by independent researchers. The fact that independent researchers were not aware of the results of the baseline assessment and were not involved in the clinic has contributed to minimizing the interviewer bias on outcomes of interest including satisfaction with the programme.

Reporting bias is a limitation of cohort studies that compare subjects' fall rates before and after intervention $[9,10,12]$. However, such bias is unlikely to fully explain the reduction in the fall-related injuries, which are less susceptible to reporting bias [24]. Besides, some studies have shown that falls recall has an acceptable sensitivity and specificity, especially when patients without moderate or severe cognitive impairment (who represent $75 \%$ of our patients) or their caregivers are interviewed [24,25].

In the present study, recommendations of the occupational therapists were based on a questionnaire and not followed by a home visit. This limitation may explain why only $58 \%$ of the recommendations given by the occupational therapist had been completed. This limitation may have reduced the impact of our programme on preventing falls and mobility impairments [10].

There may also be some limitations of telephone surveys compared to face-to-face interviews. The telephone survey has however the advantage of improving the feasibility of data collection. Moreover, the telephone survey seems to provide similar results compared with face-to-face questioning for collecting data on the risks and circumstances of falls [26]. 
Our population is different from those in other studies where participants had a lower risk of serious falls-related injuries. In the present study, $30.5 \%$ had serious fallsrelated injuries in the previous 6 months vs around 10\% in previous studies $[10,13,21]$. The effect of the intervention was larger than anticipated with a respective $80 \%$ and $42 \%$ reduction of serious and moderate fall-related injuries and a $66 \%$ reduction of the risk of falling. We believe this risk reduction to be clinically important, especially since the mobility of patients was maintained over the 6-month follow-up.

We observed a high percentage of adherence (85.7\%) to the top three proposed interventions (physiotherapy, medical review and referrals, and podiatry). In comparison with the 2 studies that have shown efficacy of the falls clinic approach in preventing injurious falls, adherence was similar to that observed in the randomizedcontrolled trial [8] but much higher than that measured in the pre-post clinic study (14.3\%) [11]. In this latter study, the more severe patients, i.e. participants with poor balance and mobility performance, were at the highest risk of loss to follow-up [11]. The high percentage of adherence to the programme that might reflect the high level of satisfaction of patients and caregivers for the information delivered during the visit $[14,28,29]$ and low drop-out percentage in our patients at high risk of injuries may have helped to optimize the effectiveness of the programme on serious falls. The fact that we prioritized a limited number of interventions may also have contributed to the good adherence to recommended interventions $[12,30]$.

Patients included in the present study were offered a wide range of assessment and management options provided by a multidisciplinary multifactorial risk assessment. Results of the present study cannot be extrapolated to non-fallers and to a morelimited range of assessment and management options. Because fall risk reduction obtained through an assessment in a fall clinic may lessen over time [27], it remains 
to be determined whether the effects on injurious falls of the multifactorial fall risk assessment described herein persist beyond the 6 months following the intervention. Finally, a study of the economic consequences of the present clinical findings is also required and a multicentre study would help to establish generalizability of our results. Based on the present results, a larger study could have the power to determine the effect of the intervention on the most costly outcomes that are fractures and admissions to hospital.

\section{Conclusions}

Fallers with recurrent falls or with balance, gait, or muscle strength problems are at a particularly high risk of new falls and injuries. These patients are unlikely to receive multifactorial falls prevention interventions in regular clinical practice. The present 6month before-after study suggests that the referral of such patients to a specialist falls prevention clinic may be associated with a reduction of the number of falls and falls-related injuries, and of the fear of falling, and may be associated with an improvement of functional status and a maintenance of mobility. The overall favourable perception of patients and caregivers for the multidisciplinary assessment, the information given about falls risk, and the recommendations provided may have helped to maximize the adherence to the programme.

\section{Contributors}

Hubert Blain contributed to study conceptualization, the investigation, project administration, study resourcing, supervision, validation, and drafting the original manuscript. 
Fiona Dabas contributed to study conceptualization, data curation, the investigation, study resourcing, and drafting the original manuscript.

Samia Mekhinini contributed to study conceptualization, data curation, the investigation, and study resourcing.

Marie-Christine Picot contributed to study conceptualization, data analysis, methodology, and software/

Stéphanie Miot contributed to study conceptualization and supervision.

Jean Bousquet contributed to study conceptualization, methodology, supervision, and drafting the original manuscript.

Chokri Boubakri contributed to study conceptualization.

Audrey Jaussent contributed to study conceptualization, data analysis, methodology, and software.

Pierre Louis Bernard contributed to study conceptualization, supervision, and drafting the original manuscript.

\section{Conflict of interest}

The authors declare that they have no conflict of interest.

\section{Funding}

This study did not receive any specific funding.

\section{Ethical approval}


Institutional ethics and research board approval was obtained. The study was approved by the Clinical Research Ethics Committee of the University Hospital of Montpellier (France)(IRB-MTP181016; ClinicalTrials.gov ID: NCT03737487).

\section{Provenance and peer review}

This article has undergone peer review.

Research data (data sharing and collaboration)

Anonymised patient-level data are available on reasonable request from the corresponding author at h-blain@chu-montpellier.fr.

\section{Acknowledgments:}

The authors are very grateful to Anna Bedbrook, for pre- and post-submission editorial assistance. 
Table 1| Patients' characteristics at baseline

\begin{tabular}{|c|c|}
\hline $\begin{array}{l}\text { Sex }[\text { No }(\%)] \\
- \text { Male }\end{array}$ & $\begin{array}{l}\mathrm{No}=134 \\
41(30.6)\end{array}$ \\
\hline - Female & $93(69.4)$ \\
\hline $\begin{array}{l}\text { Age } \\
\text { [mean, (SD)] } \\
\text { [median, (min;max)] }\end{array}$ & $\begin{array}{l}\text { No }=134 \\
81.6(7.2) \\
83.0(63.0 ; 98.0)\end{array}$ \\
\hline $\begin{array}{l}\text { Body Mass Index } \\
\text { [mean, (SD)] } \\
\text { [median, (min;max)] }\end{array}$ & $\begin{array}{l}\mathrm{No}=104 \\
25.7(4.8) \\
24.7(16.7 ; 41.7)\end{array}$ \\
\hline Living status [No (\%)] & No $=134$ \\
\hline - Home & $116(86.6)$ \\
\hline - Institution & $18(13.4)$ \\
\hline Referred by [No (\%)] & No $=128$ \\
\hline - GP & $69(53.9)$ \\
\hline - Other specialists & $22(17.2)$ \\
\hline - Emergency ward & $12(9.4)$ \\
\hline - Other hospital ward & $12(9.4)$ \\
\hline - Mobile geriatric unit & $3(2.3)$ \\
\hline - Self-referred & $4(3.1)$ \\
\hline - Other & $6(4.7)$ \\
\hline $\begin{array}{l}\text { Charlson Comorbidity Index } \\
\text { [mean, (SD)] } \\
\text { [median, (min;max)] }\end{array}$ & $\begin{array}{l}\text { No }=134 \\
5.1(1.5) \\
5(2 ; 9)\end{array}$ \\
\hline Cognitive disorders & $\mathrm{No}=127$ \\
\hline - None [No (\%)] & $75(59.1)$ \\
\hline - Mild [No (\%)] & $17(13.4)$ \\
\hline - Moderate [No (\%)] & $20(15.7)$ \\
\hline - Severe [No (\%)] & $15(11.8)$ \\
\hline One leg stand test & $\mathrm{No}=107$ \\
\hline$-<5$ seconds [No (\%)] & $84(78.5)$ \\
\hline
\end{tabular}




\begin{tabular}{|c|c|}
\hline - $\geq 5$ seconds [No (\%)] & $23(21.5)$ \\
\hline Timed Up and Go test & $\mathrm{No}=103$ \\
\hline - >20 seconds [No (\%)] & $25(24.3)$ \\
\hline - 14-20 seconds [No (\%)] & $31(30.1)$ \\
\hline - <14 seconds [No (\%)] & $47(45.6)$ \\
\hline $\begin{array}{l}\text { Grip strength } \\
-\leq 37 \mathrm{~kg} \text { in men or } \leq 21 \mathrm{~kg} \text { in women } \\
{[\text { No }(\%)]} \\
->37 \mathrm{~kg} \text { in men or }>21 \mathrm{~kg} \text { in women } \\
{[\text { No }(\%)]}\end{array}$ & $\begin{array}{l}\text { No=105 } \\
82(78.1) \\
23(21.9)\end{array}$ \\
\hline $\begin{array}{l}\text { Tinetti score } \\
\text { [mean, (SD)] } \\
\text { [median, (min;max)] }\end{array}$ & $\begin{array}{l}\mathrm{No}=87 \\
18.6(4.8) \\
18.0(9.0 ; 28.0)\end{array}$ \\
\hline $\begin{array}{l}\text { SPPB } \\
\text { [mean, (SD)] } \\
\text { [median, (min;max)] }\end{array}$ & $\begin{array}{l}\mathrm{No}=101 \\
7.7(3.3) \\
7.0(1.0 ; 20.0)\end{array}$ \\
\hline $\begin{array}{l}\text { Number of diagnostics } \\
\text { [mean, (SD)] } \\
\text { [median, (min;max)] }\end{array}$ & $\begin{array}{l}\mathrm{No}=134 \\
2.2(1.1) \\
2.0(0.0 ; 5.0)\end{array}$ \\
\hline $\begin{array}{l}\text { Number of falls } \\
\text { [mean, (SD)] } \\
\text { [median, (min;max)] }\end{array}$ & $\begin{array}{l}\mathrm{No}=134 \\
2.2(1.1) \\
2.0(0.0 ; 5.0)\end{array}$ \\
\hline $\begin{array}{l}\text { Serum } 25(\mathrm{OH}) \text { vitamin } \mathrm{D}(\mathrm{ng} / \mathrm{mL}) \\
\text { [mean, (SD)] } \\
\begin{array}{cl}- & <10 \mathrm{ng} / \mathrm{mL}[\mathrm{No},(\%)] \\
- & 10 \text { to } 30 \mathrm{ng} / \mathrm{mL}[\mathrm{No},(\%)] \\
- & >30 \mathrm{ng} / \mathrm{mL}[\mathrm{No},(\%)]\end{array}\end{array}$ & $\begin{array}{l}\text { No }=79 \\
27.6(15.6) \\
14(17.8) \\
28(35.4) \\
37(46.8)\end{array}$ \\
\hline
\end{tabular}




\begin{tabular}{|c|c|c|c|}
\hline & Baseline & $\begin{array}{l}6 \text { months } \\
\text { after clinic } \\
\text { attendance }\end{array}$ & $P$ value* \\
\hline $\begin{array}{l}\text { ADL } \\
\text { [mean, (SD)] } \\
\text { [median, (min;max)] }\end{array}$ & $\begin{array}{l}\mathrm{No}=122 \\
5.1(1.3) \\
5.5(0.0 ; 6.0)\end{array}$ & $\begin{array}{l}\text { No }=122 \\
4.8(1.6) \\
5.5(0.0 ; 6.0)\end{array}$ & $<0.001$ \\
\hline - ]0-2] [n (\%)] & $7(5.7)$ & $12(9.9)$ & 0.0430 \\
\hline - ]2-4] [n (\%)] & $17(13.9)$ & $17(13.9)$ & \\
\hline - ]4-5] [n (\%)] & $18(14.8)$ & $22(18.0)$ & \\
\hline - >5 [n (\%)] & $80(65.6)$ & $71(58.2)$ & \\
\hline Outdoor displacements [No (\%)] & $\mathrm{No}=133$ & $\mathrm{No}=133$ & $p=0.20$ \\
\hline - Do not walk & $7(5.3)$ & $15(11.3)$ & \\
\hline - With a wheelchair & $4(3.0)$ & $5(3.8)$ & \\
\hline - Walk with a walker & $14(10.5)$ & $13(9.8)$ & \\
\hline - Walk with a stick & $45(33.8)$ & $47(35.3)$ & \\
\hline - Walk with a human help & $4(3.0)$ & $8(6.0)$ & \\
\hline - Independent walking & $59(44.4)$ & $45(33.8)$ & \\
\hline Indoor displacements [No (\%)] & $\mathrm{No}=132$ & $\mathrm{No}=132$ & $p=0.21$ \\
\hline - Do not walk & $0(0.0)$ & $6(4.5)$ & \\
\hline - With a wheelchair & $2(1.5)$ & $2(1.5)$ & \\
\hline - Walk with a walker & $14(10.6)$ & $18(13.6)$ & \\
\hline - Walk with a stick & $34(25.8)$ & $20(15.2)$ & \\
\hline - Walk with a human help & $1(0.8)$ & $3(2.3)$ & \\
\hline - Independent walking & $81(61.4)$ & $83(62.9)$ & \\
\hline Fear of falling & $\mathrm{No}=95$ & $\mathrm{No}=95$ & 0.0015 \\
\hline - Not concerned [No (\%)] & $31(32.6)$ & $44(46.3)$ & \\
\hline - A little concerned [No (\%)] & $17(17.9)$ & $27(28.4)$ & \\
\hline - Quite concerned [No (\%)] & $20(21.1)$ & $11(11.6)$ & \\
\hline - Very concerned [No (\%)] & $27(28.4)$ & $13(13.7)$ & \\
\hline
\end{tabular}


Patients with Falls in the past 6 months

- No fall [No (\%)]

- Fall with no injury [No (\%)]

- Moderate injury [No (\%)]

- Serious injuries [No (\%)]
$\mathrm{No}=131 \quad \mathrm{No}=131 \quad \mathrm{p}<0.0001$

$6(4.6) \quad 89(67.9)$

$66(50.4) \quad 23(17.6)$

$19(14.5) \quad 11(8.4)$

$40(30.5) \quad 8(6.1)$ 
Table 3 | Description of the consequences associated with moderate and serious falls*

\begin{tabular}{|l|l|c|c|}
\hline \multicolumn{2}{|c|}{ Consequences } & $\begin{array}{l}\text { 6 months before } \\
\text { clinic attendance }\end{array}$ & $\begin{array}{l}\text { 6 months after } \\
\text { clinic attendance }\end{array}$ \\
\hline \multirow{5}{*}{ Moderate injuries } & $\begin{array}{l}\text { Hematoma or } \\
\text { wound }\end{array}$ & 13 & 10 \\
\cline { 2 - 4 } & Head trauma & 4 & 0 \\
\cline { 2 - 4 } & $\begin{array}{l}\text { Falls with medical } \\
\text { care }\end{array}$ & 1 & 1 \\
\cline { 2 - 4 } & $\begin{array}{l}\text { Falls with disability } \\
>48 \mathrm{~h}\end{array}$ & 1 & 0 \\
\cline { 2 - 4 } & Total & $\mathbf{1 9}$ & $\mathbf{1 1}$ \\
\hline \multirow{5}{*}{ Serious injuries } & Hip fracture & 4 & 3 \\
\cline { 2 - 4 } & Pelvis fracture & 3 & 0 \\
\cline { 2 - 4 } & Spine fracture & 6 & 0 \\
\cline { 2 - 4 } & Humeral fracture & 1 & 1 \\
\cline { 2 - 4 } & Wrist fracture & 5 & 1 \\
\cline { 2 - 4 } & $\geq 3$ ribs fracture & 3 & 2 \\
\cline { 2 - 4 } & Joint dislocation & 0 & $\mathbf{8}$ \\
\cline { 2 - 4 } & $\begin{array}{l}\text { Head trauma with } \\
\text { hospitalisation }\end{array}$ & 18 & 0 \\
\cline { 2 - 4 } & Total & $\mathbf{4 0}$ & 0 \\
\cline { 2 - 4 } & & & 0 \\
\hline
\end{tabular}

* On the model used by El-Khoury et al [16] 
Table 4| Patients' adherence to recommendations*

\begin{tabular}{lcc}
\hline & $\begin{array}{c}\text { Recommended } \\
\text { No }(\%)\end{array}$ & $\begin{array}{c}\text { Adherence } \\
\text { No (\%) }\end{array}$ \\
\hline Physiotherapy & $106(79.7)$ & $92(87.6)$ \\
\hline Podiatry & $80(62.0)$ & $74(72.6)$ \\
Footwear modification & $72(55.8)$ & \\
Textures shoe insoles & $56(43.4)$ & \\
Podiatry treatment & $53(41.4)$ & $53(58.2)$ \\
\hline Occupational therapy & $59(46.1)$ & \\
Home safety intervention & $28(21.2)$ & $15(46.9)$ \\
Technical Aid & $76(57.1)$ & $65(85.5)$ \\
\hline Adapted Physical Activity & 82.2 \\
Specialist referral & $54(40.3)$ & \\
Drug modification & $28(20.9)$ & \\
$\quad$ Withdrawal & $7(5.2)$ & \\
Decrease & $86(64.2)$ & \\
$\quad$ Increase & & \\
\hline Introduction & & \\
\end{tabular}

${ }^{*}$ Ratio (in \%) of the number of measures actually set up over the 6-month period following the visit to the number of measures prescribed during the clinic visit 


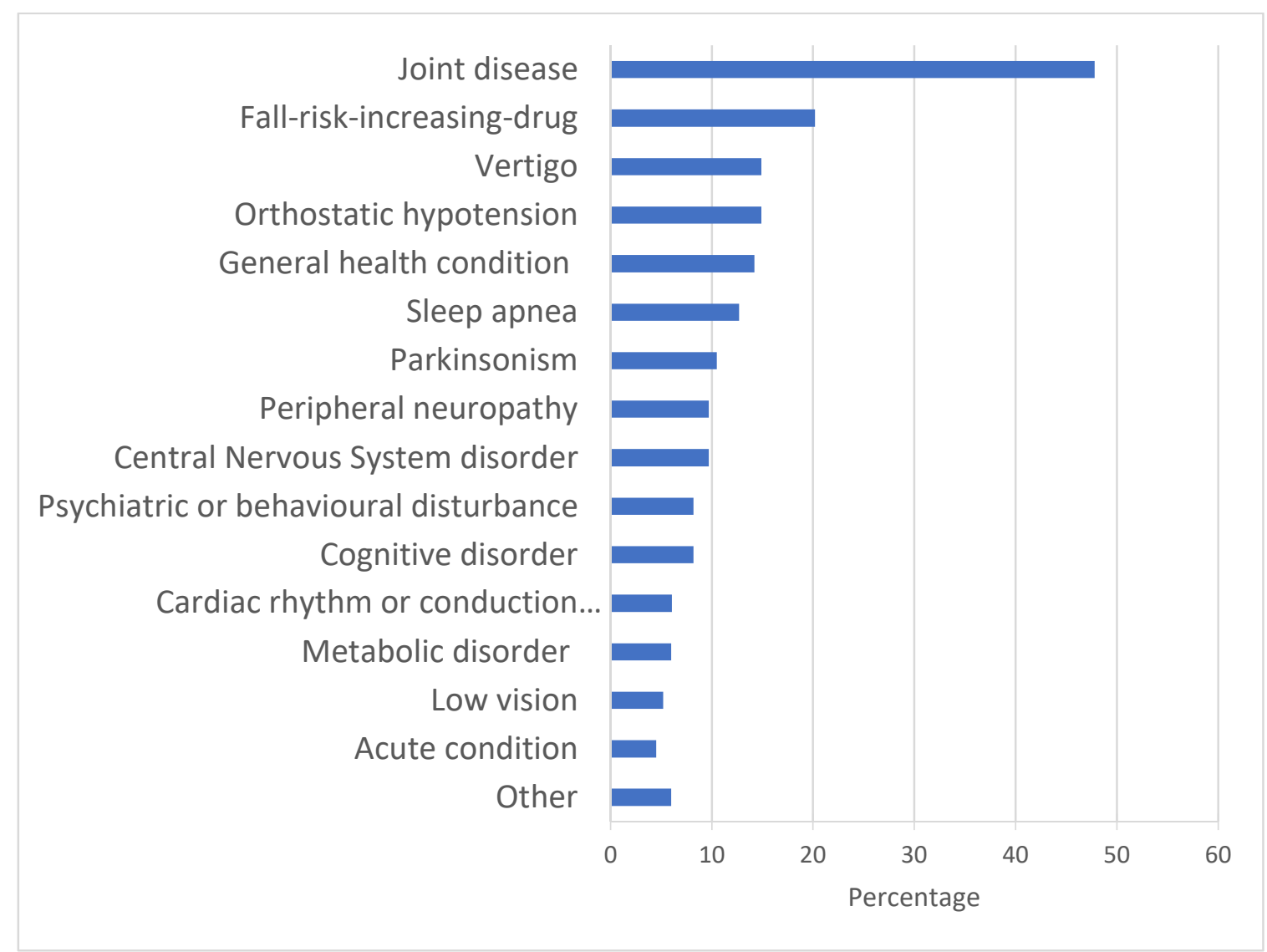

Figure 1| Main factors identified during the fall-risk assessment 
Figure 2 | Satisfaction with the programme reported 6 months after clinic attendance

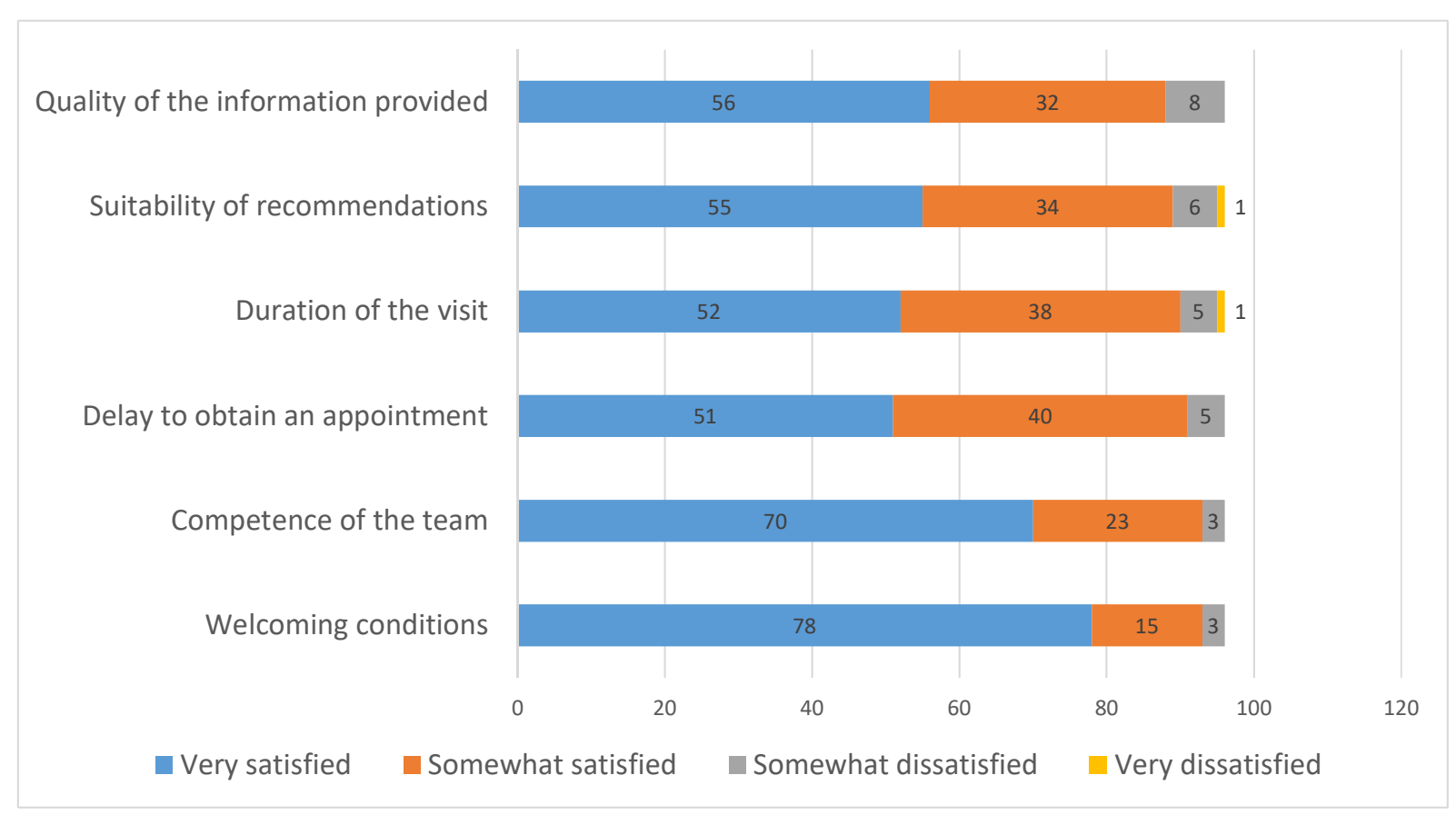




\section{References}

1 Oliver D. Falls in older people-can we really make a difference? BMJ 2018;361:k1655. doi:10.1136/bmj.k1655.

2 European Innovation Partnership on Active and Healthy Ageing (https://ec.europa.eu/eip/ageing/action-groups-eip-aha/a2-falls-prevention en)

3 Centers for Disease Control and Prevention. Stopping Elderly Accidents, Death, and Injuries (STEADI)(https://www.cdc.gov/steadi/)

4 Blain H, Masud T, Dargent-Molina P, at al. EUGMS Falls and Fracture Interest Group; European Society for Clinical and Economic Aspects of Osteoporosis and Osteoarthritis (ESCEO), Osteoporosis Research and Information Group (GRIO), and International osteoporosis Foundation (IOF). A Comprehensive Fracture Prevention Strategy in Older Adults: The European Union Geriatric Medicine Society (EUGMS) Statement. J Nutr Health Aging 2016;20:647-52. doi: 10.1007/s40520-016-0588-4.

5 Cameron ID, Gillespie LD, Robertson MC, et al. Interventions for preventing falls in older people in care facilities and hospitals. Cochrane Database Syst Rev 2012;12:CD005465. doi: 10.1002/14651858.CD005465.pub3.

6 Hopewell S, Adedire O, Copsey BJ, et al. Multifactorial and multiple component interventions for preventing falls in older people living in the community. Cochrane Database Syst Rev 2018;7:CD012221. doi: 10.1002/14651858.CD012221.pub2.

7 Panel on Prevention of Falls in Older Persons, American Geriatrics Society and British Geriatrics Society. Summary of the Updated American Geriatrics Society/British Geriatrics Society clinical practice guideline for prevention of falls in older persons. J Am Geriatr Soc 2011;59:148-57. doi: 10.1111/j.1532-5415.2010.03234.x.

8 Palvanen M, Kannus P, Piirtola M, et al. Effectiveness of the chaos Falls Clinic in preventing falls and injuries of home-dwelling older adults: a randomised controlled trial. Injury 2014;45:265-71. doi: 10.1016/j.injury.2013.03.010.

9 Perell KL, Manzano ML, Weaver R, et al. Outcomes of a consult fall prevention screening clinic. Am J Phys Med Rehabil 2006;85:882-8.

doi: 10.1097/01.phm.0000233209.49518.46

10 Sze PC, Cheung WH, Lam PS, et al. The efficacy of a multidisciplinary falls prevention clinic with an extended step-down community program. Arch Phys Med Rehabil 2008;89:1329-34. doi: 10.1016/j.apmr.2007.11.044.

11 Hill KD, Moore KJ, Dorevitch MI, Day LM. Effectiveness of falls clinics: an evaluation of outcomes and client adherence to recommended interventions. $J$ Am Geriatr Soc 2008;56 :600-8. doi: 10.1111/j.1532-5415.2007.01626.x

12 Baker DI, Leo-Summers L, Murphy TE, Katz B, Capobianco BA. Intervention to Prevent Falls: Community-Based Clinics. J Appl Gerontol 2017:733464817721113. doi: 10.1177/0733464817721113.

13 Moore M, Williams B, Ragsdale S, et al. Translating a multifactorial fall prevention intervention into practice: a controlled evaluation of a fall prevention clinic. J Am Geriatr Soc 2010;58:357-63. 
doi: 10.1111/j.1532-5415.2009.02683.x.

14 Clemson L, Cumming RG, Kendig $\mathrm{H}$ et al. The effectiveness of a community based program for reducing the incidence of falls in the elderly: A randomized trial. J Am Geriatr Soc 2004;52:1487-94.

doi: 10.1111/j.1532-5415.2004.52411.x

15 Blain H, Abecassis F, Adnet PA, et al. Living Lab Falls-MACVIA-LR: The falls prevention initiative of the European Innovation Partnership on Active and Healthy Ageing (EIP on AHA) in Languedoc-Roussillon. European Geriatric Medicine 2014;5:416-25.

https://ec.europa.eu/eip/ageing/library/living-lab-falls-macvia-Ir-fallsprevention-initiative-european-innovation-partnership_en

16 El-Khoury F, Cassou B, Latouche A, et al. Effectiveness of two year balance training programme on prevention of fall induced injuries in at risk women aged 75-85 living in community: Ossébo randomised controlled trial. BMJ 2015;351:h3830. doi: 10.1136/bmj.h3830.

17 Podsiadlo D, Richardson S. The timed "Up \& Go": A test of basic functional mobility for frail elderly persons. J Am Geriatr Soc 1991;39:142-8.

Doi: 10.1111/j.1532-5415.1991.tb01616.x

18 Vellas BJ, Wayne SJ, Romero LJ, et al: One-leg balance is an important predictor of injurious falls in older persons. J Am Geriatr Soc 1997;45:735-8. doi: 10.1111/j.1532-5415.1997.tb01479.x

19 Pijnappels M, van der Burg PJ, Reeves ND, van Dieen JH. Identification of elderly fallers by muscle strength measures. Eur J Appl Physiol 2008;102:58592. doi: 10.1007/s00421-007-0613-6

20 Guralnik JM, Ferrucci L, Simonsick EM, Salive ME, Wallace RB. Lowerextremity function in persons over the age of 70 years as a predictor of subsequent disability. N Engl J Med 1995;332:556-61.

Doi: 10.1056/NEJM199503023320902

21 Tinetti ME, Gordon C, Sogolow E, et al. Fall-risk evaluation and management: Challenges in adopting geriatric care practices. Gerontologist 2006;46:717-25. doi: $10.1093 /$ geront/46.6.717

22 Jette AM. Toward a common language of disablement. J Gerontol A Biol Sci Med Sci 2009;64:1165-8. Doi: 10.1093/gerona/glp093

23 Vellas BJ, Wayne SJ, Romero LJ, et al: Fear of falling and restriction of mobility in elderly fallers. Age Ageing 1997;26:189-93. PMID: 9223714

24 Ganz DA, Higashi T, Rubenstein LZ. Monitoring falls in cohort studies of community-dwelling older people: effect of the recall interval. J Am Geriatr Soc 2005;53:2190-4. doi: 10.1111/j.1532-5415.2005.00509.x

25 Sanders KM, Hayles AL, Kotowicz MA, Nicholson GC. Monitoring falls in cohort studies of community-dwelling older women. J Am Geriatr Soc 2009;57:733-4. doi: 10.1111/j.1532-5415.2009.02205.x

26 Mackintosh S, Fryer C, Hill K. Telephone and face-to-face interviews generate similar falls circumstances information from community-dwelling adults with stroke. Aust N Z J Public Health 2009;33:295-6. 
doi: 10.1111/j.1753-6405.2009.00392.x

27 Wagner EH, LaCroix AZ, Grothaus L, et al. Preventing disability and falls in older adults: A population-based randomized trial. Am J Public Health 1994; 84:1800-6. PMID: 7977921 PMCID: PMC1615188

28 McInnes E, Askie L. Evidence review on older people's views and experiences of falls prevention strategies. Worldviews Evid Based Nurs 2004;1:20-37. doi: 10.1111/j.1741-6787.2004.04013.x

29 Hill KD, Day L, Haines TP. What factors influence community-dwelling older people's intent to undertake multifactorial fall prevention programs? Clin Interv Aging 2014;9:2045-53. doi: 10.2147/CIA.S72679.

30 Hill KD. Don't lose sight of the importance of the individual in effective falls prevention interventions. BMC Geriatr 2009;9:13. doi: 10.1186/1471-2318-913. 